\title{
Estudio legal empírico sobre el uso del Derecho Comparado por parte del Tribunal Constitucional de Chile*
}

\author{
Amaya Álvez Marin** \\ Benjamin Vicente Vielma***
}

\begin{abstract}
RESUMEN
Este trabajo es un estudio legal empírico acerca del uso del Derecho Comparado por parte del Tribunal Constitucional de Chile entre el 2006 y 2012. Luego de comprobar el uso relevante del Derecho Comparado como parte de la argumentación de las sentencias del Tribunal Constitucional en el período examinado, se realiza un análisis descriptivo acerca del cumplimiento formal de esas referencias, y otro relativo al motivo de las mismas en tanto importa nociones jurídicas desconocidas, complementa o fortalece las normas internas invocadas. Finalmente, se analiza el empleo de la referencia comparada para delimitar la resolución jurídica del caso, confirmar la decisión ya adoptada o mostrar una alternativa jurídica diversa a la del fallo. En definitiva, sobre la base de datos legales empiricos inéditos se responde la pregunta de investigación relativa al rol relevante, estratégico o meramente decorativo que tienen las referencias de Derecho Comparado en la jurisprudencia del tribunal.
\end{abstract}

Derecho Comparado - constitucionalismo empírico - justicia constitucional

* Artículo elaborado como parte del proyecto Fondecyt $\mathrm{N}^{\circ} 11121371$, Teoría y Práctica del Derecho Comparado por parte del Tribunal Constitucional Chileno 2006-2012, apoyo académico que agradecemos sinceramente. Asimismo quisiera reconocer el trabajo de investigación de los memoristas de pregrado de la Carrera de Derecho que trabajaron en el presente proyecto: M.E. Cisternas, J. Herrera, D. Lagos, L. Muñoz, J. Norambuena, C. Ramírez, M. Vallejos, N. Velásquez, B. Vicente, L. Wong, y R. Zapata, Agradecemos los comentarios formulados por dos árbitros anónimos y por el Dr. Sergio Toro. Los errores por supuesto solamente son imputables a la investigadora principal Dra. Alvez.

** Licenciada en Ciencias Jurídicas y Sociales, Universidad de Concepción. Doctora en Derecho, Universidad de York, Canadá. Profesora de los Departamentos de Derecho Público y de Historia y Filosofía del Derecho, Facultad de Ciencias Jurídicas y Sociales, Universidad de Concepción. Correo electrónico: aalvez@udec.cl

*** Licenciado en Ciencias Jurídicas y Sociales, Universidad de Concepción. Correo electrónico: bvicente@udec.cl

Artículo recibido el 31 de marzo de 2017 y aceptado para su publicación en este número el 23 de julio de 2018. 


\title{
Empirical legal study on the use of comparative law by the Constitutional Court of Chile
}

\begin{abstract}
This paper is an empirical legal study on the use of comparative law by the Constitutional Court of Chile between the years 2006-2012. After verifying the relevant use of comparative law as part of the arguments of the Constitutional Court rulings, a descriptive analysis is offered on the formal fulfillment of these references, and another data was built on the motives exposed by the Court, either the transplant of unknown legal solutions, or a simple complement or addition to the internal norms. Finally, we examine the possible uses of comparative references: demarcate the legal resolution of the case, to confirm the decision already adopted or to show a different legal alternative. Finally, on the basis of unpublished empirical legal data, we answered the research question regarding the relevant, strategic or merely decorative role of comparative law references in the jurisprudence of the Constitutional Court.
\end{abstract}

Comparative law - empirical constitutionalism - constitutional justice

\section{INTRODUCCIÓN}

$\mathrm{E}$

1 Derecho Comparado nace como ciencia que lograría la convergencia entre diversos sistemas jurídicos mediante la armonización y unificación del derecho positivo entre naciones civilizadas ${ }^{1}$. Esta disciplina jurídica representa "la comparación de los sistemas jurídicos actuales o los elementos particulares de los mismos, en la búsqueda de una variedad de objetivos académicos y prácticos" ${ }^{2}$. Desde una perspectiva externa, el Derecho Comparado es frecuentemente considerado como el estudio de "materias extranjeras o simplemente foráneas”, y tiende a menudo a ser confundido con el derecho internacional ${ }^{3}$. Algunos comparatistas postulan que los paradigmas básicos del Derecho Comparado han sido puestos en duda ${ }^{4}$. Este proceso de modernización ya ha sido propuesto desde una mirada latinoamericana, perspectiva que excede el presente artículo5.

${ }^{1}$ Fauvarque-Cosson, B., "Development of Comparative Law in France", en Reimann M. \& Zimmermann R. (eds.), The Oxford Handbook of Comparative Law, Oxford, UK: Oxford University Press, 2008, p. 43.

2 Reiman M., "Comparative Law and Neighbouring Disciplines”, en Busani M. y Mattei U. (eds.), Cambridge Companion to Comparative Law, London, UK: Cambridge University Press, 2012, p. 34.

${ }^{3}$ Groppi, T. \& Ponthoreau, Marie-Claire (eds.), The Use of Foreign Precedents by Constitutional Judges, Hart Studies in Comparative Public Law, Oxford and Portland, Oregon, Hart Publishing, 2013, p. 3.

${ }^{4}$ Muir Watt, H., "Globalization and Comparative Law", en Reimann M. \& ZimmermanN R. (eds.), The Oxford Handbook of Comparative Law, Oxford, UK: Oxford University Press, 2008, pp. 583-607.

${ }^{5}$ López-Medina, D., "El nacimiento del Derecho Comparado moderno como espacio geográfico y como disciplina; instrucciones básicas para su comprensión y uso desde América Latina”, en Revista Colombiana de Derecho Internacional, Vol. 26, 2015, pp. 117-159. 
El trabajo que aquí se presenta pretende superar parcialmente la crítica de ausencia de una metodología para el uso del Derecho Comparado. El método usado por investigaciones empíricas busca hacerse preguntas respecto del fenómeno legal, juntar evidencia respecto del uso de una determinada institución jurídica para luego interpretar esa evidencia y formular algunas conclusiones. Hasta ahora no se ha avanzado en conectar los estudios teóricos del derecho con los empíricos, a pesar de la evidente conveniencia de probar factualmente aquello que se esgrime en teoría y, a su vez, la posibilidad de conectar las preguntas de investigación como parte de una teoría jurídica. Los estudios legales empíricos examinan el modo en que el derecho opera en la realidad aplicado por las autoridades o en el modo en que es recepcionado por sus destinatarios. Esta curiosidad natural por examinar cómo el derecho opera en la práctica, conlleva la pregunta por los fines del derecho o los bienes jurídicos que intenta proteger. Este objetivo, que en definitiva está conectado con el ideal de justicia social, ha hecho que teóricos del derecho argumenten que los trabajos empíricos tienen un rol relevante en sus estudios ${ }^{6}$.

En Chile, el Derecho Comparado constitucional ha tenido un desarrollo incipiente por parte de los autores nacionales. Precursores fueron artículos de doctrina publicados por Humberto Nogueira el $2011^{7}$, a los que le siguió Liliana Galdámez el $2012^{8}$, y nuevamente el académico Humberto Nogueira el 20139 , todos se enfocaron en analizar con detalle y de manera específica sentencias del Tribunal Constitucional chileno, y cómo estas en ciertos fallos hacían uso del Derecho Comparado. Para efectuar este análisis los autores proponen agrupar las sentencias de acuerdo con similitudes y diferencias. Sin embargo, ninguno de estos relevantes trabajos abordó el tema desde una metodología empírica, y por ello consideramos que este es el aporte específico de la presente investigación.

\section{Marco Metodológico de UnA INVESTigación LEGAL EMPÍricA}

Este trabajo es un estudio legal empírico, esto es "una recolección sistemática de información (datos) y su análisis conforme a un método jurídico"10. Así, Herbert Kritzen indica que "el rasgo distintivo de los estudios legales empíricos, es el uso de

${ }^{6}$ Twining, W., General Jurisprudence: Understanding Law from a Global Perspective, Cambridge: Cambridge University Press, 2009 y Leiter, B., Naturalizing Jurisprudence, Oxford: Oxford University Press, 2007.

${ }^{7}$ Nogueira, H., "El uso del derecho extranjero y del derecho internacional por parte del tribunal constitucional chileno durante el período 2006-2007”, en Revista de Derecho de la Pontificia Universidad Católica de Valparaíso, núm, XXXVII, 2011.

${ }^{8}$ GALDÁmEz, L., "El uso del derecho y jurisprudencia extranjera en los fallos del Tribunal Constitucional de Chile: 2006-2010”, en Revista Chilena de Derecho, Vol. 39, núm, 1, año 2012.

9 Nogueira, H., "El uso del derecho y jurisprudencia constitucional extranjera y de tribunales internacionales no vinculantes por el tribunal constitucional chileno en el período 2006-2011”, en Estudios Constitucionales, núm. 1, 2013.

${ }^{10}$ Cane, P. \& Kritzert, H., "The Oxford Handbook of Empirical Legal Research”, Oxford University Press, segunda edición, 2010, p. 4. 
datos, sistemáticamente recolectados, ya sea de una manera cualitativa o cuantitativa, para describir o analizar un fenómeno legal"11. El autor advierte que hasta hace poco tiempo existía un entendimiento rudimentario de la obtención de los muestreos en donde luego se recolectan los datos, lo que hacía muy difícil y poco probable la obtención de conclusiones que representen a la población completa a ser estudiada por la investigación empírica. La misma crítica ha sido formulada por Ran Hirschl, respecto de los estudios comparativos en derecho constitucional, ya que considera que no son lo suficientemente rigurosos metodológicamente en la selección de los casos: "La referencia a jurisprudencia constitucional extranjera -por lo general jurisprudencia en materia de derechos fundamentales- es ecléctica, a veces incluso escasa y superficial. La selección de los casos rara vez es sistemática, y tampoco presta la debida atención al contexto y los matices que dan lugar a interpretaciones similares o alternativas o a la práctica de las normas constitucionales" 12 . El hecho de que Hirschl no proponga cómo deberían participar los jueces en el razonamiento comparativo, resalta la necesidad de hacerse cargo de este vacío metodológico en el uso de la herramienta comparada. Se trata de un método de investigación poco desarrollado en el ámbito jurídico local, pero de potente desarrollo en otras latitudes. Judith Schönsteiner ha publicado uno de los pocos estudios legales empíricos existentes en Chile relativo al uso del derecho internacional de los derechos humanos por parte del Tribunal Constitucional en Chile ${ }^{13}$.

De acuerdo con Nielsen, planificamos nuestro trabajo en etapas, con una primera etapa de orden cualitativo mediante el análisis de documentos, lo que permitió la construcción de una hipótesis y condujo la investigación a una segunda etapa más profunda y de orden cuantitativo de recolección de datos ${ }^{14}$. Este método ha sido objeto de críticas basado en la imprecisión de qué aspectos podrían constituir un análisis sistemático con ribetes de investigación científica ${ }^{15}$. Aquí conviene recordar que "la investigación cualitativa es particularmente buena para examinar si un fenómeno social particular existe o no, y su naturaleza. Y es menos útil para evaluar la extensión y distribución del fenómeno, lo que es mejor dejado a una investigación cuantitativa" ${ }^{16}$.

${ }^{11}$ Kritzert, H., “The (Nearly) Forgotten Early Empirical Legal Research”, en Cane, P. \& Kritzert, H., The Oxford Handbook of Empirical Legal Research, Oxford University Press, segunda edición, 2010, p. 14.

12 Hirschl, R., "The Question of Case Selection in Comparative Constitutional Law", The American Journal of Comparative Law, Vol. LIII: 1, 2005, pp. 125-156.

${ }^{13}$ SCHÖnsteiner, J., "El derecho internacional de los derechos humanos en el Tribunal Constitucional chileno: el mínimo común denominador", Revista de Derecho Universidad Austral de Chile, Año 29, Vol. 1, 2016, pp. 197-226.

${ }^{14}$ Nielsen, L., "The Need for Multi-Method Approaches in Empirical Legal Research”, en Cane, P. \& Kritzer, H., The Oxford Handbook of Empirical Legal Research, Oxford University Press, segunda edición, 2010, p. 954 .

15 Barriga, O. y Henríquez, G. "El Plano Alfa del Objeto de Estudio", Cinta de Moebio, 2005, diciembre, $\mathrm{N}^{\circ} 024$.

${ }^{16}$ Webley, L., "Qualitative Approaches to Empirical Legal research”, en Cane, P. \& Kritzer, H., The Oxford Handbook of Empirical Legal Research, Oxford University Press, segunda edición, 2010, pp. 941-944. 
Esta investigación persigue mediante un análisis inductivo alcanzar dos objetivos, el primero de ellos es dar una visión descriptiva del universo en análisis, esto es sentencias definitivas del Tribunal Constitucional chileno, que nos permitan entender el contexto donde nuestra investigación se desarrolla, y luego, el segundo objetivo es crear categorías conceptuales acerca del uso del Derecho Comparado de parte del Tribunal Constitucional de Chile.

Nosotros realmente no utilizaremos un "muestreo" que posteriormente deba seguir reglas estadísticas para poder obtener conclusiones representativas de la población total a la que el muestreo pertenezca, sino que se buscará un análisis total del universo de interés, esto porque "hacer inferencias respecto de más datos que de menos es siempre preferible" 17 . Luego de determinado el objeto de estudio, esto es la totalidad de sentencias definitivas del Tribunal Constitucional en el período examinado, proponemos la codificación de variables para su posterior extracción.

\section{ANÁlisis DE DERECHOS INVOCADOS, INTERVINIENTES Y ORÍGENES GEOGRÁFICOS DE LA REFERENCIAS}

\section{Primeros datos estadísticos}

Una idea central y que debe permear todos los análisis efectuados en este trabajo es la afirmación que el uso de Derecho Comparado, esto es derecho foráneo no vinculante, es de carácter voluntario por parte de la autoridad, en este caso jueces constitucionales, que adoptan la decisión jurídica interna. Esto ratifica que la fuerza del Derecho Comparado es argumental, si se considera que el Derecho Comparado forma parte de la argumentación, ya sea en un rol preponderante, estratégico o meramente decorativo. Por ello es relevante el estudio pormenorizado de los modos en que los jueces deciden hacer uso del Derecho Comparado, pues ello implica fijar las bases de futuros estudios relativos a la denominada "fase de descubrimiento", esto es el estudio de los factores que inciden en la toma de decisiones por parte del juez ${ }^{18}$.

El estudio de documentos se basó únicamente en las sentencias dictadas por el Tribunal Constitucional en el período comprendido entre el 2006 y 2012. Se estudió la totalidad de la labor resolutiva en los años mencionados, es decir, seis años de actividad de la magistratura constitucional. Esto nos permitió, primero, aseverar con certeza la

17 Epstein, L. \& Martin, A. (2010), “Quantitative Approaches to Empirical Legal Research”, en CAne, P. \& Kritzer, H., The Oxford Handbook of Empirical Legal Research, Oxford University Press, segunda edición, 2010, p. 910.

${ }^{18}$ JaCKson, V., “Constitutional Comparisons: Convergence, Resistance, Engagement”, en Harvard Law Review, Vol. 119 No 1, Nov. 2005, pp. 109-128. 
realidad de dicho período, y luego tener un estudio lo suficientemente amplio como para proyectar esas conclusiones a la fecha de la salida de los resultados ${ }^{19}$.

El total de documentos que fueron objeto de esta primera etapa de estudio empírico ascendió a 1453 resoluciones judiciales. Nuestro trabajo fue acotado a 721 sentencias definitivas, ya que de dicho total solo ese número de requerimientos fueron admitidos a tramitación declarándolos admisibles, y 732 fueron resueltos con una declaración de inadmisibilidad o improcedencia, quedando por ello fuera de este análisis ${ }^{20}$.

El próximo punto de interés fue diferenciar aquellos requerimientos conocidos en el fondo de aquellos que no superaron la prueba formal de admisibilidad, ordenándolos según su naturaleza, esto basado en las causales que les dan sustento legal en el artículo 93 de la Constitución Política de la República que trata de las atribuciones del Tribunal Constitucional. De esta segunda aproximación es destacable señalar que 144 de los requerimientos corresponden al numeral $1^{\circ}$, esto es, el control de constitucionalidad a priori vinculante respecto de las leyes interpretativas, leyes orgánicas constitucionales y a las normas de un tratado que versen acerca de materias propias de ley orgánica constitucional. La mayor parte de las sentencias examinadas, esto es 504 de los requerimientos, invocaban al numeral $6^{\circ}$, esto es el control de constitucionalidad consistente en la inaplicabilidad de un precepto legal cuya aplicación resulte contraria a la Carta Fundamental que la Ley $\mathrm{N}^{\circ} 20.050$ del año 2005 entregó al Tribunal Constitucional quitándole la facultad de conocer de estas causas a la Corte Suprema que la detentaba desde la Constitución de $1925^{21}$. Las causas que invocaban el numeral $6^{\circ}$ es el $69,90 \%$ de todos los casos conocidos por el Tribunal Constitucional en el período examinado. Esto es relevante, ya que significó la apertura del Tribunal Constitucional a la ciudadanía.

Una vez conocida la relevancia porcentual del numeral $6^{\circ}$ del artículo 93, fue necesario conocer qué artículos de la Constitución Política son sometidos a control de parte de los requirentes en estos casos. A este análisis decidimos también agregar aquellos casos del numeral $7^{\circ}$, esto es el control de constitucionalidad en abstracto que permite expulsar un precepto legal del ordenamiento jurídico y que corresponden a 8 casos. Lo anterior nos llevó en primera instancia a delimitar el estudio empírico considerando como variables a los artículos que van desde el $1^{\circ}$ al $19^{\circ}$ de la Constitución Política de la República, y el resultado fue que de 1.592 preceptos legales invocados para ser objeto de control constitucional, 1.249, es decir el 78,45\% de los casos, los que estaban siendo invocados eran numerales del artículo $19^{\circ}$.

Este dato numérico mayoritario a su vez nos presentó la oportunidad de hacer una diferenciación más, ahora mirando únicamente a los numerales de dicho artículo para intentar identificar la existencia de alguna tendencia. Es interesante observar que derechos

${ }^{19}$ Cada una de las resoluciones judiciales examinadas fueron codificadas mediante una ficha que recababa aspectos formales (rol, partes, naturaleza del requerimiento, disposiciones constitucionales) y substantivos de la sentencia definitiva (materia del caso, decisión para luego identificar el uso de Derecho Comparado en una o en la otra).

${ }^{20}$ Hicimos codificación cruzada y se observó coincidencia entre estas.

${ }^{21}$ Ley de reforma constitucional 20.050 publicada en el Diario Oficial el 26 de agosto de 2005. 
fundamentales que no están protegidos por otras acciones constitucionales, como es el recurso de protección, resultaran muy invocados. Es el caso del derecho a la seguridad social.

Tabla 1. Derechos fundamentales invocados en los requerimientos

$$
\text { Art. } 93 \mathrm{~N}^{\mathrm{os}} 6 \text { y } 7
$$

\begin{tabular}{lcc}
\hline Derecho fundamental invocado & Consagración positiva & Dato empírico No invocaciones \\
\hline Debido proceso & Art. $19 \mathrm{~N}^{\circ} 3$ & 240 \\
\hline Igualdad ante la ley & Art. $19 \mathrm{~N}^{\circ} 2$ & 213 \\
\hline Propiedad individual privada & Art. $19 \mathrm{~N}^{\circ} 24$ & 195 \\
\hline Contenido esencial DDFF & Art. $19 \mathrm{~N}^{\circ} 26$ & 178 \\
\hline Derecho a la salud & Art. $19 \mathrm{~N}^{\circ} 9$ & 116 \\
\hline Derecho a la seguridad social & Art. $19 \mathrm{~N}^{\circ} 18$ & 103 \\
\hline
\end{tabular}

Fuente: Elaboración propia, $\mathrm{N}=1.045$.

Respecto de los intervinientes, distinguimos cuatro tipos de intervinientes: persona natural, persona jurídica, órgano del Estado, y juez. Las primeras dos categorías se ciñen a lo enunciado en el Código Civil, luego la tercera hace referencia a aquellos casos donde tanto un juez, ministro, juzgado, Tribunal o Corte solicita la resolución de la controversia constitucional sometida a su decisión, lo que en Derecho Comparado se ha denominado "duda de constitucionalidad". Por último, tenemos a los "órganos del Estado" que representan a todas aquellas entidades públicas que se entiende ejercen una labor pública y que forman parte de la organización del Estado, esto es, que gozan de una personalidad jurídica de derecho público.

Tabla 2. Requirentes en las causas de control represivo del Tribunal Constitucional (Art. $95 \mathrm{~N}^{\mathrm{os}} 6$ y 7)

\begin{tabular}{lcc}
\hline Tipo requirente & Dato numérico & Representación porcentual \\
\hline Persona natural & 485 & 64 \\
\hline Persona jurídica & 223 & 29 \\
\hline Tribunales de Justicia & 36 & 5 \\
\hline Órgano del Estado & 12 & 2 \\
\hline
\end{tabular}

Fuente: Elaboración propia, $\mathrm{N}=756$. 
Respecto de los requirentes, el mayor número porcentual corresponde a personas naturales, lo que marca el nuevo ámbito de competencia entregado por la reforma constitucional del 2005 al Tribunal Constitucional. También marca la concepción de la aplicación directa de la Constitución al ser, en numerosas ocasiones, los requirentes órganos del Estado ${ }^{22}$. Finalmente, también es una novedad la facultad de los jueces de elevar la pregunta respecto de la constitucionalidad de un precepto legal al intérprete concentrado de constitucionalidad en nuestro ordenamiento. Respecto de los requeridos, el mayor número corresponde a órganos del Estado, lo que permite inducir que en nuestro sistema se ha incorporado una aplicación vertical del catálogo de derechos fundamentales que enfrenta a los ciudadanos con los órganos estatales. Debemos también señalar que es posible la multiplicidad de requirentes en la misma acción.

\section{El uso de la categoría Derecho Comparado}

El Derecho Comparado es definido por algunos como el estudio de los "trasplantes legales”, esto es, homologable a un préstamo de ideas entre culturas jurídicas en el tiempo ${ }^{23}$. Para otros, el Derecho Comparado persigue primordialmente explorar la relación entre el derecho y la cultura legal ${ }^{24}$, centrándose en las mentalidades y percepciones de la ley en un espacio y tiempo determinados, observando cómo las normas jurídicas "oficiales" conviven con otras fuentes (supranacionales o nacionales) no oficiales del derecho ${ }^{25}$.

El presente trabajo persigue fundamentalmente examinar este debate a la luz de un ejemplo concreto, el caso del Tribunal Constitucional chileno a partir de su reestructuración el 2005. Por ello la hipótesis es genérica, pero los datos examinados corresponden a ese Tribunal en particular y durante el período entre el 2006 y 2012. Para este trabajo legal empírico conceptualizaremos Derecho Comparado como "cualquiera fuente de carácter doctrinal, jurisprudencial, legislativo u genérico que tenga su origen en el extranjero y que no constituya una fuente internacional vinculante en el ámbito doméstico". Es necesario distinguir la fuente foránea de aquellas fuentes internacionales que forman parte del ordenamiento constitucional por medio de la norma de reenvío contenida en el art. $5^{\circ}$ de la Constitución de 1980. Con esto claro, y volviendo al análisis documental, encontramos presencia de Derecho Comparado en 240 de las sentencias definitivas, dejando entonces a 481, más de dos tercios, fundándose única y exclusivamente en fuentes de origen nacional.

${ }^{22}$ Esto ha sido debatido intensamente por la doctrina extranjera como es el caso de Aharon BARAK, Proporcionalidad: los derechos constitucionales y sus limitaciones, Cambridge University Press, 2012.

${ }^{23}$ La obra clásica al respecto es Watson A. Legal Trasplants: An approach to Comparative Law, Athens, Georgia, USA: University of Georgia Press, 2a edición, 1993.

${ }^{24}$ Cotterrell, R., "Comparative Law and Legal Culture", en Reimann, M. \& Zimmenrmann, R. (eds.), The Oxford Handbook of Comparative Law, Oxford, UK: Oxford University Press, 2008, pp. $710-737$.

${ }^{25}$ GLENN P., Legal Traditions of the World: Sustainable Diversity in Law, Oxford, UK, Oxford University Press, $4^{\mathrm{a}}$ edición, 2010. 
Así como nos preguntamos en su momento la naturaleza de los requerimientos que fueron admitidos en general, ahora nos hacemos la misma interrogante mirando exclusivamente los casos en que había presencia de Derecho Comparado en la sentencia definitiva. Los requerimientos de inaplicabilidad por inconstitucionalidad, consagrado en el numeral 6 del artículo 93 de la Constitución Política, constituyen la mayoría de los casos, alcanzando el $87,9 \%$ del total. De ellos, en el 41,86\% de los casos resueltos por el Tribunal Constitucional en esta materia se recurrió en la resolución del caso al Derecho Comparado como disciplina. En el caso del control de constitucionalidad a priori o preventivo, la cantidad de casos en que se usa Derecho Comparado es mínimo, solo en el 6,25\% de los casos se utiliza esta herramienta disciplinar. Siendo por ejemplo mucho más relevante la situación del requerimiento de inaplicabilidad por inconstitucionalidad, esto es, el principal mecanismo de control de constitucionalidad en abstracto consagrado en el numeral 7 del artículo 93, donde en el 75\% de los casos hubo presencia de Derecho Comparado. Sumando ambos controles de constitucionalidad represivo, la suma indica que el 90,41\% de las sentencias definitivas que tienen presencia de Derecho Comparado han sido competencia del Tribunal Constitucional por el control ubicado en el Art. $93 \mathrm{~N}^{\text {os }} 6$ o 7.

Gráfico 1. Naturaleza del requerimiento y su relación con Derecho Comparado

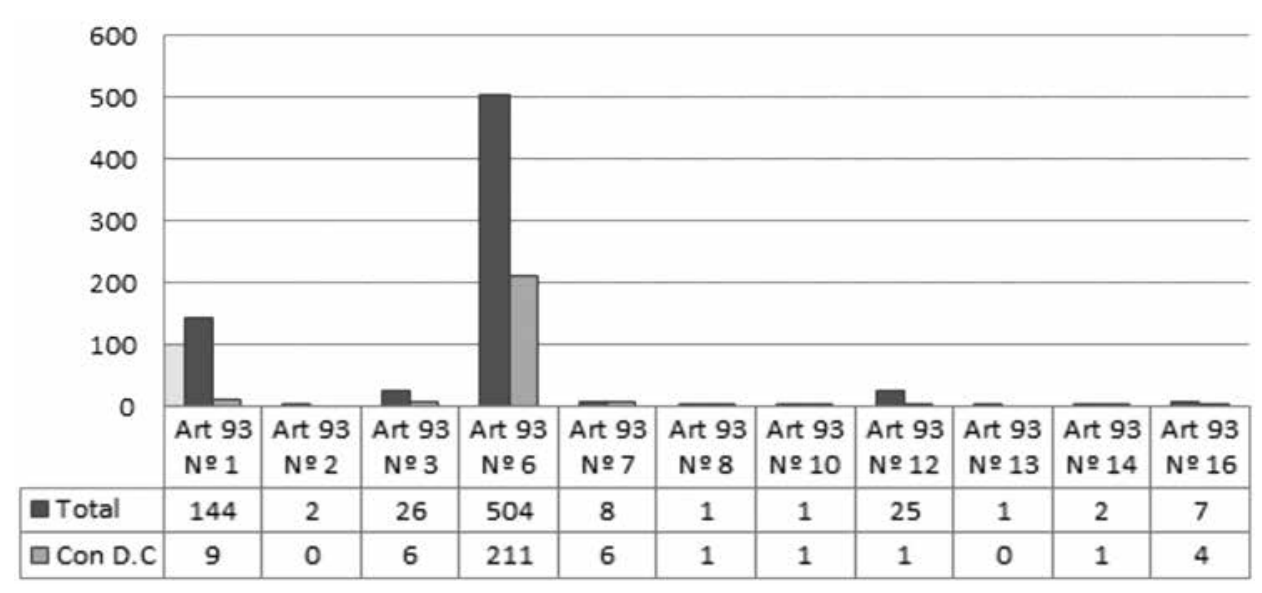

Fuente: Elaboración propia, $\mathrm{N}=961$.

Por tanto, del mismo concepto se desprendía que el Derecho Comparado como disciplina puede ser utilizado tanto por la doctrina, las resoluciones judiciales y la legislación, y un último elemento denominado genérico, que presenta elementos de Derecho Comparado, pero que no respondía a una de las categorías examinadas. Ahora, respecto de estos elementos, refiriéndonos a los cuatro señalados, nos toca precisarlos 
individualmente para poder dar a entender mejor la forma en que fueron extractados los datos de las fuentes y que, desde este punto, serán el objeto de estudio principal del proyecto.

Como doctrina se entiende toda aquella cita o alusión a autores que no son de nacionalidad chilena referente a ordenamientos jurídicos foráneos. Sentencias son aquellas resoluciones de tribunales de justicia que no tienen reconocida jurisdicción en el territorio nacional y que resuelvan la controversia sometida a su decisión. Legislación se refiere a cualquier tipo de norma jurídica que no tenga su origen en el poder legislativo de Chile o pueda llegar a tener fuerza obligatoria en el territorio nacional; y por último, el concepto de referencia genérica son todas aquellas citas o referencias que no puedan ser clasificadas en ninguno de los criterios principales que componen el concepto de Derecho Comparado $^{26}$. Es en este punto donde la base principal de este trabajo adquiere forma. Es aquí que logramos el primer acercamiento concreto y objetivo de la presencia del Derecho Comparado en las 240 sentencias definitivas del Tribunal Constitucional que ya señalamos, identificando 1.212 citas o referencias del mismo, de estas, 662 corresponden a doctrina, 281 a sentencias, 170 a legislación y, por último, 99 a referencias genéricas.

\section{Orígenes geográficos de las citas comparadas}

Con anterioridad nos referimos al criterio rector para identificar cómo comparada una cita o referencia, este era el de ser extranjero o foráneo respecto del punto de origen donde se utiliza, en nuestro caso Chile. Por ello, una inquietud que aflora naturalmente es la referencia al origen de esas referencias. Para responder a esta inquietud nos centramos entonces en estas 1.212 citas o referencias, a las que se les intentó identificar un origen, lo que fue sencillo en algunos casos como en las citas de legislación, ya que el propio texto mencionaba el mismo, y en otros tomó algo más de trabajo, como es el caso de la doctrina o las referencias genéricas, donde hubo que ahondar la investigación, ya que el solo análisis del documento no nos podía brindar esta información.

De lo anterior, en el caso de la doctrina y sus 673 citas $^{27}$, España predomina teniendo el 43,09\% del total de citas comparadas de este elemento, luego le sigue de lejos Alemania y Francia con $13,81 \%$ y 12,92\%, respectivamente, siendo entonces el $69,83 \%$ de los casos concentrados en estos tres países europeos. Otro aspecto a destacar es el hecho de que sean 18 los distintos orígenes geográficos detectados, lo que muestra cierta amplitud que contrasta con lo dicho anteriormente relativo a la concentración de referencias eurocéntricas.

${ }^{26}$ Una referencia amorfa la encontramos en la Sentencia Rol No 2.153-11 de fecha 11/9/2012, en cuyo considerando 36 del Tribunal "Este es también el parecer que ha primado en la legislación comparada y en las decisiones de los tribunales internacionales...".

${ }^{27}$ El total no coincide con el total de citas de Doctrina, ya que en 11 (673 total) casos se encontraron autores con doble nacionalidad, y para hacer el gráfico lo más representativo al origen se decidió asignar en esos casos un valor a cada país de origen. 
A continuación, en el caso de las 281 citas de sentencias de tribunales de justicia foráneos, vemos nuevamente a España con la mayoría de referencias con 44,12\%, bastante similar al caso de doctrina, y quienes lo siguen ahora son Colombia y Alemania, con $12,45 \%$ y $11,74 \%$, respectivamente. El mismo patrón es destacable en esta ocasión, siendo 3 orígenes, dentro de 16, quienes se llevan el 68,32\% de las citas. La única variación aquí sería que el segundo puesto lo toma Colombia y no Francia, que muestra algo de presencia sudamericana en este tipo de citas comparadas. Por supuesto que en este aumento de referencias latinoamericanas se basa en el prestigio alcanzado por la Corte Constitucional colombiana desde su creación en 1991.

El caso de la legislación no comparte tanto rasgos con los anteriores, excepto por el hecho de que España nuevamente es el origen mayoritario de las citas comparadas, teniendo 34 de las 170 apariciones. Esto corresponde a 20\% del total, lo que ya delata una mayor homogeneidad en cuanto a los orígenes, pues de los 20 posibles ocho de estos cuentan con 9 o más reiteraciones.

El último tipo de referencia son las denominadas referencias de naturaleza genérica. Esta categoría de cita o referencia es de difícil implementación en esta etapa del estudio debido a la imprecisión de la información disponible, sin embargo se decidió efectuar igualmente el ejercicio. El resultado fueron 99 citas y del análisis se encontró que el 39,39\% de los casos corresponden a un origen no identificable, lo que podría hacer variar significativamente el conteo de los demás 16 orígenes encontrados, esto si presumimos que correspondan a alguno de ellos. Esto da cuenta de la necesidad de implementar una metodología apropiada en el uso del Derecho Comparado por parte de las institucionales nacionales, entre ellas el Tribunal Constitucional.

Por último, nos queda ahora presentar la sumatoria total de los elementos, de ver cómo se comportan las citas de Derecho Comparado en su concepto amplio, sumando entonces los números obtenidos de doctrina, sentencias, legislación y genérico. Así, podemos ver cómo la tendencia que se marcó en los tres principales elementos naturalmente hace que el Gráfico 2 represente a España con una mayoría, que corresponde al 37,69\% de los casos. Algo atenuada se ve su representación, ya que al sumar los elementos la base de orígenes ascendió a 29, distribuyendo más el total base de este caso que eran 1.223 citas o referencias comparadas.

A modo de conclusión, en todos los tipos de referencias, de modo mayoritario, un grupo pequeño de países europeos concentra la mayoría de las citas o referencias. Vemos cómo $64,75 \%$ de las citas pertenecen a España, Alemania, Francia e Italia, dejando a Argentina y Colombia como los únicos seguidores más cercanos, con un total sumado de $8,9 \%$. Esta diferencia Europa-Sudamérica se acrecentaría aún más si consideramos el origen denominado como "Unión Europea" que se vio en los casos de sentencias y legislación, donde si se suma a los ya mencionados cuatro países europeos, incrementa su total a 68,02\%, más de dos tercios del total encontrado. El estudio de las razones que explican esta dependencia eurocéntrica exceden los límites del presente estudio. 
Gráfico 2. Origen geográfico general de las Citas Comparadas del período

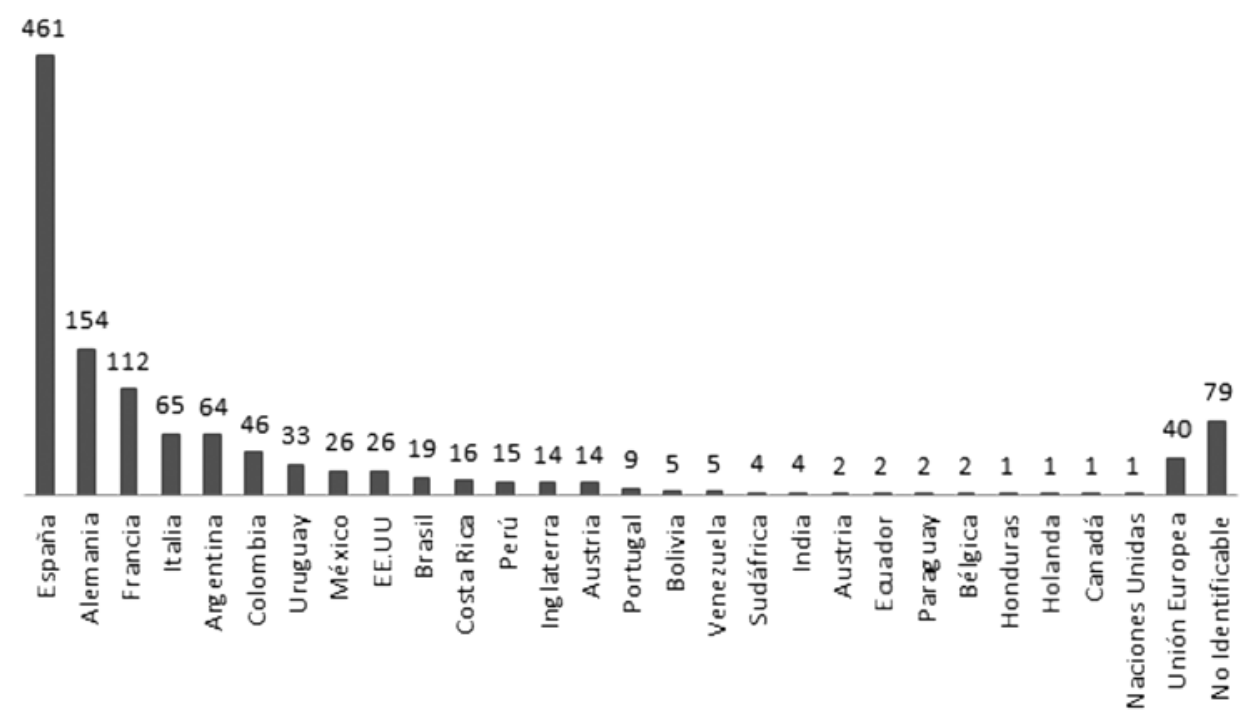

Fuente: Elaboración propia, $\mathrm{N}=1.223$.

\section{ANÁlisis de aspectos formales, MOtivo de LA REFERENCIA COMPARADA Y ANÁLISIS DE SU USO EN LA SENTENCIA}

En la sección anterior hemos presentado un estudio cualitativo de las referencias de Derecho Comparado efectuadas por el Tribunal Constitucional de Chile entre el 2006 y 2012 en materia de derechos constitucionales examinados, partes requirentes, categorías de Derecho Comparado y orígenes geográficos de las mismas. Al analizar los datos obtenidos surgen nuevas inducciones que responden a la pregunta de investigación respecto del modo en que fueron usadas las citas o referencias comparadas por parte del Tribunal Constitucional chileno. Este análisis dio lugar a tres categorías de análisis de las referencias de Derecho Comparado.

La primera categoría de análisis se origina en los aspectos formales de cada cita(s) o referencia(s) comparada(s), es decir, las distintas formulaciones escritas en las que se consagraban respecto de un parámetro ideal propio de la investigación jurídica. La segunda categoría de análisis corresponde a la razón o motivación que llevó al Tribunal Constitucional a incorporar la cita o referencia comparada, entendiéndose como un elemento del desarrollo argumentativo de la sentencia. La tercera categoría de análisis es el posicionamiento que la cita o referencia comparada ocupa dentro de la sentencia definitiva, ya mirada como un todo completo. Con ello retomamos la pregunta de investigación inicial relativa al rol relevante, estratégico o meramente decorativo que tienen las referencias de Derecho Comparado en la jurisprudencia del tribunal. Estas 
tres categorías de análisis se transformaron en tres aspectos novedosos de la investigación legal empírica que surgieron gracias al paso cualitativo, y sin esto no se pudieran haber creado los modelos teóricos de los esquemas que se utilizarán en la próxima etapa cuantitativa de este trabajo.

\section{Las fuentes del argumento}

Una debilidad general de los argumentos jurídicos es la inexistencia de normas homologadas de citación ${ }^{28}$. Ello también afecta la labor de los jueces. No existen criterios a los que los jueces deban ceñirse dentro de su labor. Por esto mismo es que en el caso de las citas y referencias comparadas, aun siendo de la misma naturaleza, existen modos muy diversos de presentarlas en la sentencia definitiva. Debido al carácter de tribunal colegiado, y al hecho que dentro del período 2006-2012 hubo cambios en la integración del Tribunal Constitucional (nuevos integrantes), cada ministro con un estilo propio de redacción y uso de las referencias comparadas es difícil establecer un patrón único. Sin embargo, se pudieron detectar tendencias de uso para cada uno de los elementos, ciertas tendencias que manifestaban en algunos casos citas o referencias marcadamente más "completas" 29 en cuanto a la información que contenían en ella, antes de entrar al fondo de lo que la cita propiamente dice. Por lo mismo es que tanto para doctrinas, sentencias, legislación y referencias genéricas comparadas se crearon lo que llamaremos "modelos ideales de forma", según estas, cada una de las citas o referencias que fueron sometidas a este modelo, es decir, las 1.212, debían cumplir con los requisitos o elementos de este modelo ideal de forma. La elaboración de un criterio mínimo formal se justifica con la necesidad de establecer cierto parámetro para que cualquier persona que entre en conocimiento de la cita o referencia comparada pueda volver a ella sin mayores problemas, es decir, volver a la fuente original. La importancia de este ejercicio radica en que la base de cualquier proceso de citas consiste en reconducir la cita a la fuente de donde se obtuvo lo citado, constituyéndose como un sello de validez.

El primer modelo formal será el de doctrina, que como adelantamos contiene cinco elementos formales, primero el nombre, el que consideramos como cumplido al citar el nombre del artículo o texto del que se extrae la cita o referencia, al autor(es), la editorial o revista que se refiere a la encargada de la difusión de la obra, y en el caso de ser un artículo, la revista en la que está contenida, después el año de la publicación de la obra o texto y por último el de la(s) página(s) de las que se extrae la cita o referencia. Con esto veremos que las 662 citas o referencias comparadas debieran cumplir cada una con estos 5 elementos, alcanzando un porcentaje de conformidad al modelo de $88,48 \%$.

Ahora respecto de los elementos que componen el modelo teórico formal de las sentencias, el primero es el rol o nombre, luego tenemos a la magistratura, que sería

${ }^{28}$ López-Medina, D., Las Fuentes del Argumento, Bogotá: Editorial Legis, $3^{a}$ reimpresión, 2011.

${ }^{29}$ Como referencia para el establecimiento de un parámetro ideal, se tomaron en cuenta las exigencias mínimas de fondo que establecen las Normas Internacionales ISO 690: 1987, ISO 690-2: 1997 e ISO 690-2010. 
aquella que dictó la sentencia, seguimos con el país, que se refiere a la jurisdicción de la magistratura mencionada, el año hace alusión al que fue dictada la sentencia y por último el considerando dice relación con la ubicación dentro de la sentencia, si es que no es una alusión completa, donde se ubica la cita o referencia extractada. Lo anterior, tomando en cuenta la base de 281 sentencias, refleja que solamente 55,23\% de las referencias comparadas muestra conformidad a este parámetro ideal.

El tercer modelo formal corresponde a la legislación, comenzando por el número o nombre, el que es el de la norma jurídica en cuestión, después se incluye la naturaleza de la norma, le sigue el país y año, siendo el primero al que pertenece la legislación aludida y el año de su entrada en vigencia ${ }^{30}$ y por último el artículo, a no ser que sea una referencia general a la legislación completa. Las citas o referencias comparadas en materia de legislación cumplieron al 92,58\%, alcanzando hasta ahora, dentro de los tres principales elementos del Derecho Comparado, el puntaje de conformidad formal más alto.

Por último tenemos nuevamente el genérico, que por su peculiar naturaleza hace difícil presentarle un modelo ideal. Sin embargo, y al igual que en el caso del origen geográfico, se intentó dar un modelo propio que le fuera compatible, el que consta solo de tres elementos, partiendo por contexto o introducción que podría entenderse satisfecho al hacer un referencia al contexto del que se extrae. Los otros elementos son el país y año, para ello nos remitimos a lo dicho en los otros casos. El cumplimiento del total alcanzado fue muy bajo, llegando a $25,58 \%$.

Gráfico 3. Modelo de cumplimiento formal de referencias comparadas

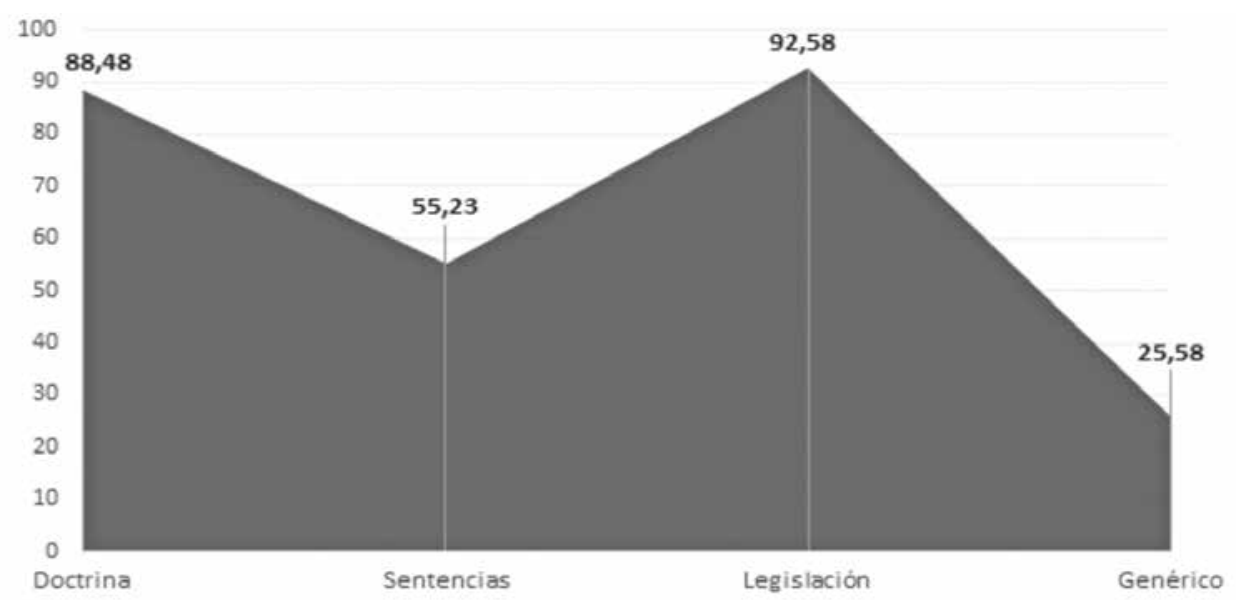

Fuente: Elaboración propia, $\mathrm{N}=5.862$.

${ }^{30}$ Para el caso de las constituciones, aun no señalando el año, se consideró como año el de la sentencia definitiva del Tribunal Constitucional en la que se usó. 
Una última cosa respecto de este análisis de forma es el hecho de que el único elemento que se midió en los cuatro elementos fue la referencia del origen temporal de la cita o referencia, lo que también nos deja ver un poco el rango de años en los que los jueces constitucionales buscan las fuentes comparadas. Esto nos deja dos conclusiones importantes: la primera de ellas es el hecho de que la mayoría de las veces no se sobrepasa un rango más allá de los 20 o 30 años, concentrándose $71 \%$ de estos casos dentro de ese margen temporal. La otra conclusión que se puede extraer es el hecho de que una importante cantidad, 23,43\%, de las veces no se señaló el año de la cita o referencia.

\section{Análisis del motivo de la referencia de Derecho Comparado}

Este punto fue especialmente importante para la investigación, ya que busca entender o comprender la posible motivación del juez constitucional para el uso de una referencia de Derecho Comparado en la resolución judicial adoptada. Nuevamente hablaremos de 1.212 citas y referencias, las que por medio de un examen y una vez identificados ciertos patrones de semejanza en su uso, se llegó a un modelo que podía abarcar cada una de las citas mencionadas sin que ninguna quedara fuera de lugar, o forzadamente incorporada. Esta función del ejercicio comparado ha sido limitadamente tratado por la doctrina nacional ${ }^{31}$.

Es posible señalar que un rol importante en este trabajo fue el ejercicio comparado que significó para nosotros la existencia de citas o referencias nacionales, que fueron en definitiva las que nos ayudaron a confirmar el que se haya efectuado o no el ejercicio comparado. La primera de las tres acciones que se proponen en relación con el uso del Derecho Comparado por parte del juez constitucional en Chile se denominó importar Derecho Comparado con fuerza argumental, la segunda fortalecer el derecho nacional a través de una referencia de Derecho Comparado y la última complementar el derecho nacional a través de una referencia de Derecho Comparado. Consideramos que este era un modo de contestar parcialmente la pregunta de investigación, ya que el uso del Derecho Comparado por parte del juez constitucional podría significar expandir la forma de pensar acerca de los argumentos posibles, las tendencias legales y las estructuras disponibles para la toma de decisiones al utilizar referencias comparadas desconocidas en nuestro ordenamiento. O en el caso de tratarse de referencias comparadas utilizadas en el caso concreto como un argumento de autoridad, para examinar mejor las fundamentaciones de las sentencias ya adoptadas sobre la base del ordenamiento nacional, o complementando el propio sistema jurídico con información substantiva proveniente de la referencia de Derecho Comparado.

Nos encontraremos ante una importación de Derecho Comparado en los casos que se utiliza la cita o referencia comparada de manera aislada, esto en relación con las de orden nacional, manifestándose con ella una idea, concepto o conclusión novedosa o desconocida

${ }^{31}$ Ferrante, A., "Entre Derecho Comparado y Derecho Extranjero. Una aproximación a la comparación jurídica”, en Revista Chilena de Derecho, Vol. 43 N², agosto 2016, pp. 601-618. 
en el ordenamiento jurídico, sin poder detectar otra referencia de orden nacional que aluda directamente o indirectamente al mismo tópico. Esta categoría es la que se intenta abarcar en aquellas situaciones en las que sin más se incorpora en una sentencia una referencia o cita comparada, y que si se analiza en el mismo considerando, o en aquellos que le son adyacentes y que tratan la misma idea jurídica, no encontraremos otra cita o referencia del orden nacional que pueda complementar lo que esa referencia de Derecho Comparado intenta aportar. Esta categoría siempre se presenta aislada, o acompañada de otras referencias comparadas, pero nunca con un soporte de índole nacional. De este concepto que entregamos es que podemos extraer los elementos que lo componen, y que por tanto son necesarios que concurran para encontrarnos ante esta categoría: i) una referencia o cita de Derecho Comparado aislada; ii) manifestar un concepto, enunciado o razonamiento desconocido en nuestro ordenamiento nacional.

Estamos ante la categoría de fortalecer el derecho nacional mediante una referencia de Derecho Comparado cuando se utiliza la cita o referencia comparada como un argumento complementario a aquellos de origen nacional, es por tanto necesario precisar que, aún sin esta referencia comparada, se podría arribar la idea, concepto o conclusión jurídica que se intenta manifestar en la sentencia, siendo entonces suficiente la de origen nacional para alcanzar dicho objetivo. Los elementos que lo componen, y que por tanto son necesarios que concurran para encontrarnos ante esta categoría: i) una referencia o cita de Derecho Comparado acompañada de una o más fuentes de origen nacional de cualquier naturaleza; ii) robustecer o reafirmar la manifestación de un concepto, enunciado o razonamiento, la cual podría fundarse de manera suficiente solo con la fuente de origen nacional. En esta categoría entonces vamos a encontrar siempre a la cita o referencia comparada acompañada de una o más referencias de orden nacional, y es entonces importante que se puedan hacer las conexiones necesarias entre estas y que se pueda también detectarse que se refieren al mismo tema, para así no confundirla con una “importación de Derecho Comparado”. Otro aspecto a destacar de esta categoría es que para nosotros no es determinante el hecho de cuál es el orden en el que aparecen tanto las citas nacionales como comparadas. Es decir, que si primero aparecen las de orden nacional y luego las comparadas refiriéndose a lo mismo, se entenderá configurada esta categoría, pero si es al contrario y primero aparece la de carácter comparado y posteriormente la nacional, no entenderemos que existió una "importación de Derecho Comparado", sino que al concurrir ambos elementos descritos anteriormente habrá una intención de "fortalecer el derecho nacional a través de una referencia de Derecho Comparado".

Por último, estamos ante la categoría de complementar el derecho nacional mediante una referencia de Derecho Comparado en aquellas situaciones en que existe una cita o referencia comparada y una o más de orden nacional, ambas referentes a un mismo tema dentro del considerando o en los adyacentes, pero que la cita o referencia comparada aporta nueva información de carácter sustantivo. De este concepto que entregamos es que podemos extraer los elementos que lo componen, y que por tanto son necesarios que concurran para encontrarnos ante esta categoría: i) Forma: una referencia o cita 
de Derecho Comparado acompañada de una o más fuentes de origen nacional de cualquier naturaleza; ii) Fondo: robustecer un concepto enunciado o razonamiento respecto de un cierto tema, el que puede fundarse de manera suficiente con solo la fuente de origen nacional, pero que además entrega información nueva de carácter sustantivo. Esta clasificación guarda ciertas semejanzas con las dos categorías que la anteceden. Primero, en relación con la categoría de fortalecer el derecho nacional por medio de una referencia de Derecho Comparado vemos que ambas presentan una estructura de forma idéntica, pero la complementación del derecho nacional mediante una referencia de Derecho Comparado va un paso más allá, y es aquí donde se asemeja más a nuestra primera categoría de importación de Derecho Comparado con fuerza argumental, pues si bien se encuentra acompañada de una fuente de origen nacional que trata del mismo tema, lo que las acerca es que aporta algo nuevo a la sentencia, y por tanto algo diferente a su correlativo nacional. Ahora este aporte debe ser categorizado como sustantivo, entendiendo cumplido este requisito con cualquiera que no signifique una mera reformulación de lo ya dicho, sino que importe a la incorporación algo novedoso, que nos permite avanzar en el desarrollo argumental del fallo, o que nos facilite una mejor comprensión de aquello que se está tratando.

Gráfico 4. Motivo de las referencias de Derecho Comparado (2006-2012)

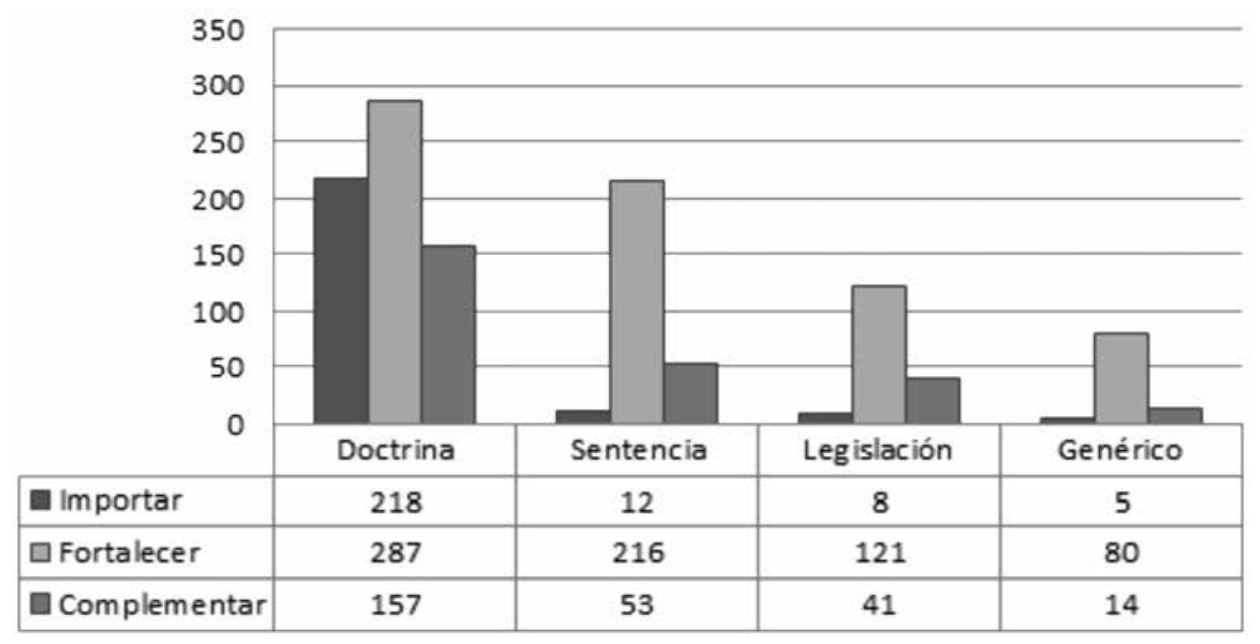

Fuente: Elaboración propia, $\mathrm{N}=1.212$.

La inmensa mayoría de las referencias comparadas son complementarias a decisiones jurídicas ya adoptadas de acuerdo con la normativa interna. Se utiliza por ello como un argumento de autoridad con una finalidad decorativa o de estilo. 


\section{Conclusiones}

Al conocer los resultados del análisis formal que se realizó a las citas o referencias comparadas, nos pudimos percatar que si bien el porcentaje de cumplimiento superaba en algunos casos lo que podría estimarse como aceptable, el parámetro que se estableció era un mínimo necesario para reconstruir el puente entre la cita y la fuente. El no recrear esta conexión vulnera en parte la legitimidad de la argumentación, cayendo en una falta de transparencia de la que los jueces constitucionales parecen no estar al tanto. Esto se hace más grave si volvemos atrás y lo relacionados con la primera etapa de investigación, donde observamos que la gran mayoría de los requerimientos que fueron resueltos por el Tribunal Constitucional eran interpuestos por personas naturales o jurídicas, quienes acudían en busca de solucionar conflictos al amparo de los numerales $6^{\circ}$ y $7^{\circ}$ del artículo 93 de la Constitución Política de la República, especialmente los casos de apertura hacia la ciudadanía de la justicia constitucional.

Dejamos en claro anteriormente que la motivación del juez constitucional para usar Derecho Comparado es una interrogante que corresponde a la denominada fase de descubrimiento del juez y que al menos en Chile aún no ha sido abordada. Primero debemos destacar que de la propia naturaleza de la categoría fortalecer el derecho nacional con una referencia comparada, que se llevó en Doctrina el 43,35\% de las citas, en Sentencias el $76,86 \%$, en Legislación el $71,17 \%$ y por último en Genérico el 80,80\%, si nosotros hiciéramos el ejercicio de eliminarla mentalmente de la sentencia definitiva, no se produciría efecto alguno. Podríamos borrar entonces de las 1.212 citas o referencias 704 y no se encontraría ninguna dificultad en llegar a la misma conclusión jurídica de constitucionalidad o inconstitucionalidad según sea lo resuelto en el caso concreto por el Tribunal Constitucional. Esto hace por lo menos reflexionar si es realmente importante o no el uso de esta herramienta comparada.

Por otro lado, la categoría importar Derecho Comparado como fue descrita en páginas anteriores, supone una incorporación a secas al texto de la sentencia definitiva, sin mediar en ningún momento con alguna fuente nacional o con algún esbozo de recepción a nuestra realidad. Es un trasplante directo de una realidad foránea, lo que también sugiere preguntar si es realmente este ejercicio de incorporar una manifestación del Derecho Comparado, ya que realmente no hubo nunca una comparación, procedimiento necesario y fundante por el que de la observación de dos realidades se obtiene una conclusión. Esta importación o trasplante jurídico, que es aquello que se busca al mirar hacia el exterior, se dio en 243 de las 1.212 referencias.

Por último, la categoría que realmente, a nuestro criterio, realiza algo cercano a un ejercicio comparado, la que realmente aporta algo a la sentencia definitiva y su desarrollo, y que debe ser estudiada con mayor detalle es la categoría de complementar el derecho nacional mediante una referencia comparada, la que alcanza solamente 265 apariciones.

En la mayoría de los casos el Tribunal Constitucional chileno utiliza la referencia de Derecho Comparado al adoptar la decisión del asunto sometido a su conocimiento. Ello implica aceptar que ante la pregunta de investigación se encuentra comprobada la relevancia argumentativa del Derecho Comparado. Esto abriría la puerta para buscar 
el modo en que las referencias comparadas se transformaran en una posibilidad para acceder a modos diversos de solución de las controversias jurídicas. Como bellamente lo propone Gunther Frankenberg, podríamos mirar el Derecho Comparado como "una aventura intelectual, una experiencia de aprendizaje, una oportunidad para estudio, la reorganización de los conocimientos y para lograr intimidad con el mundo" 32 . Ello implicaría abandonar la zona cómoda en que el Derecho Comparado opera como una referencia de autoridad decorativa.

\section{BiBLIOGRAFÍA}

Barak, A., Proporcionalidad: los derechos constitucionales y sus limitaciones, Cambridge University Press, 2012.

Bernal-Pulido, C., "El precedente en Colombia", en Revista Derecho de Estado, No 21, diciembre-2008, pp. 91-92.

Cane, P. \& Kritzert, H., The Oxford Handbook of Empirical Legal Research, Oxford University Press, segunda edición, 2010.

Cotterrell R., "Comparative Law and Legal Culture", en Reimann M. \& Zimmenrmann R. (eds.), The Oxford Handbook of Comparative Law, Oxford, UK: Oxford University Press, 2008, pp. 710-737.

GaLdÁmez, L., "El uso del derecho y jurisprudencia extranjera en los fallos del Tribunal Constitucional de Chile: 2006-2010”, en Revista Chilena de Derecho, Vol. 39, núm, 1, año 2012.

Epstein, L. \& Martin, A., "Quantitative Approaches to Empirical Legal Research", en Cane, P. \& Kritzer, H., The Oxford Handbook of Empirical Legal Research, Oxford University Press, segunda edición, 2010.

Fauvarque-Cosson B., "Development of Comparative Law in France", en Reimann M. \& Zimmermann R. (eds.), The Oxford Handbook of Comparative Law, Oxford, UK: Oxford University Press, 2008.

Ferrante, A., "Entre Derecho Comparado y Derecho Extranjero. Una aproximación a la comparación jurídica”, en Revista Chilena de Derecho, Vol. 43 N 2, Ago. 2016.

Frankenberg, G., "Critical Comparisons: Re-thinking Comparative Law”, en Harvard International Law Journal, Vol. 26, 1985, pp. 412.

GLENN P., Legal Traditions of the World: Sustainable Diversity in Law, Oxford, UK, Oxford University Press, $4^{a}$ edición, 2010.

Groppi, T. \& Ponthoreau, Marie-Claire (eds.), The Use of Foreign Precedents by Constitutional Judges, Hart Studies in Comparative Public Law, Oxford and Portland, Oregon, Hart Publishing, 2013.

Kritzert, H., "The (Nearly) Forgotten Early Empirical Legal Research”, en Cane, P. \& Kritzert, H., The Oxford Handbook of Empirical Legal Research, Oxford University Press, segunda edición, 2010.

Hirschl, R.,"The Question of Case Selection in Comparative Constitutional Law", The American Journal of Comparative Law, Vol. LIII: 1, 2005, pp. 125-156.

${ }^{32}$ Frankenberg, G., "Critical Comparisons: Re-thinking Comparative Law”, en Harvard International Law Journal, Vol. 26, 1985, pp. 412. 
JACKson, V., "Constitutional Comparisons: Convergence, Resistance, Engagement", en Harvard Law Review, Vol. 119 N 1, Nov. 2005, pp. 109-128.

LeIter, B., Naturalizing Jurisprudence, Oxford: Oxford University Press, 2007.

López-Medina, D., "El nacimiento del Derecho Comparado moderno como espacio geográfico y como disciplina; instrucciones básicas para su comprensión y uso desde América Latina", en Revista Colombiana de Derecho Internacional, Vol. 26, 2015.

López-Medina, D., Las Fuentes del Argumento, Bogotá: Editorial Legis, $3^{a}$ reimpresión, 2011.

Muir Watt, H., "Globalization and Comparative Law", en Reimann M. \& Zimmermann R. (eds.), The Oxford Handbook of Comparative Law, Oxford, UK: Oxford University Press, 2008.

Nielsen, L., "The Need for Multi-Method Approaches in Empirical Legal Research", en Cane, P. \& Kritzer, H., The Oxford Handbook of Empirical Legal Research, Oxford University Press, segunda edición, 2010.

Nogueira, H., "El uso del derecho extranjero y del derecho internacional por parte del tribunal constitucional chileno durante el período 2006-2007”, en Revista de Derecho de la Pontificia Universidad Católica de Valparaíso, núm. XXXVII, 2011.

Nogueira, H., "El uso de las comunicaciones transjudiciales por parte de las jurisdicciones constitucionales en el Derecho Comparado chileno", en Estudios Constitucionales, núm. 2, 2011.

Nogueira, H., "El uso del derecho y jurisprudencia constitucional extranjera y de tribunales internacionales no vinculantes por el tribunal constitucional chileno en el período 20062011”, en Estudios Constitucionales, núm. 1, 2013.

Reiman, M., "Comparative Law and Neighbouring Disciplines", en Busani M. y Mattei U. (eds.), Cambridge Companion to Comparative Law, London, UK: Cambridge University Press, 2012.

SChÖNSTEINER, J., "El derecho internacional de los derechos humanos en el Tribunal Constitucional chileno: el mínimo común denominador", Revista de Derecho Universidad Austral de Chile, Año 29, Vol. 1, 2016, pp. 197-226.

Twining, W., General Jurisprudence: Understanding Law from a Global Perspective, Cambridge: Cambridge University Press, 2009.

Watson, A., Legal Trasplants: An approach to Comparative Law, Athens, Georgia, USA: University of Georgia Press, $2^{a}$ edición, 1993.

Webley, L., "Qualitative Approaches to Empirical Legal research”, en Cane, P. \& Kritzer, H., The Oxford Handbook of Empirical Legal Research, Oxford University Press, segunda edición, 2010. 